\title{
Value of Endolymphatic Hydrops and Perilymph Signal Intensity in Suspected Ménière Disease
}

(D).M. van Steekelenburg, (D) A. van Weijnen, (D) L.M.H. de Pont, (D) O.D. Vijlbrief, (D)C.C. Bommeljé, (D).P. Koopman, (D)B.M. Verbist, (D) H.M. Blom, and (D)S. Hammer

\begin{abstract}
BACKGROUND AND PURPOSE: Ménière disease is characterized by endolymphatic hydrops, whereas perilymphatic enhancement on MR imaging has been suggested to be of additional value in diagnosing Ménière disease. This study evaluates the presence of endolymphatic hydrops and perilymphatic enhancement in patients with Ménière disease and with other vertigo-associated inner ear pathology.
\end{abstract}

MATERIALS AND METHODS: A 3D-FLAIR sequence 4 hours after intravenous gadolinium injection was performed to visualize the endolymph and perilymph in 220 patients suspected of having Ménière disease. Patients' ears were retrospectively categorized as having Ménière disease (probable or definite) or other vertigo-associated inner ear pathology not attributable to Ménière disease. Endolymphatic hydrops was evaluated using a visual classification system, and perilymphatic enhancement was scored both visually and quantitatively.

RESULTS: Endolymphatic hydrops was present in 137 (91.9\%) of the definite Ménière disease ears and in 9 (7.0\%) of the ears with other vertigo-associated inner ear pathology $(P<.001)$. The combination of endolymphatic hydrops and visually increased perilymphatic enhancement was present in $122(81.9 \%)$ definite Ménière disease ears compared with 4 (3.1\%) ears with other vertigo-associated inner ear pathology $(P<.001)$. This combination increases the positive predictive value from 0.94 for endolymphatic hydrops and 0.91 for perilymphatic enhancement to 0.97 . The addition of measured perilymphatic enhancement leads to a moderate decrease in sensitivity from 0.92 for endolymphatic hydrops to 0.86 .

CONCLUSIONS: The combination of perilymphatic enhancement and endolymphatic hydrops in patients suspected of having Ménière disease increases the positive predictive value in the diagnosis of definite Ménière disease.

ABBREVIATIONS: $\mathrm{EH}=$ endolymphatic hydrops; $\mathrm{MD}=$ Ménière disease; $\mathrm{PE}=$ perilymphatic enhancement; SIR = signal intensity ratio; VAIEP $=$ vertigoassociated inner ear pathology

M énière disease $(\mathrm{MD})$ is characterized by attacks of vertigo, low-frequency hearing loss, and tinnitus. In the absence of a diagnostic standard, clinical diagnostic criteria were defined by the American Academy of Otolaryngology-Head and Neck Surgery and updated into a consensus of diagnostic guidelines by

Received September 7, 2019; accepted after revision January 1, 2020.

From the Departments of Radiology (J.M.v.S., L.M.H.d.P., S.H.) and

Otorhinolaryngology (A.v.W., C.C.B., J.P.K., H.M.B.), Haga Teaching Hospital, The Hague, the Netherlands.; Department of Radiology (O.D.V.), Ziekenhuis Groep Twente, Almelo, the Netherlands; and Department of Radiology (B.M.V.), Leiden University Medical Centre, Leiden, the Netherlands

J.M. van Steekelenburg and A. van Weijnen are shared first author; H.M. Blom and S. Hammer are shared senior authors.

This work was supported by the Radiology Research Fund of the Radiological Society of the Netherlands.

Paper previously presented at: Annual Meeting of the European Society of Neuroradiology, September 19-23, 2018, Rotterdam, the Netherlands; Annual Meeting of the European Society of Head and Neck Radiology, September 27-29, 2018, Kensington, UK; and Annual Meeting of the European Congress of Radiology, February 27-March 3, 2019, Vienna, Austria. the Bárány Society in 2015. This includes 2 distinct diagnostic entities: definite and probable $\mathrm{MD}$, based on differences in vertigo episode duration and documented low-frequency hearing loss. ${ }^{1}$ Because key clinical symptoms overlap other clinical entities such as vestibular migraine, it remains difficult to distinguish MD from other vertigo-associated inner ear pathologies. ${ }^{2-4}$

Although the etiology of MD remains unclear, endolymphatic hydrops $(\mathrm{EH})$ is generally accepted as the pathologic hallmark of the disease. ${ }^{5}$ 3T MR imaging after delayed intravenous gadolinium allows visualization of the endolymphatic space, with $\mathrm{EH}$ findings similar to histopathologic findings. ${ }^{6,7}$ However, $\mathrm{EH}$ is

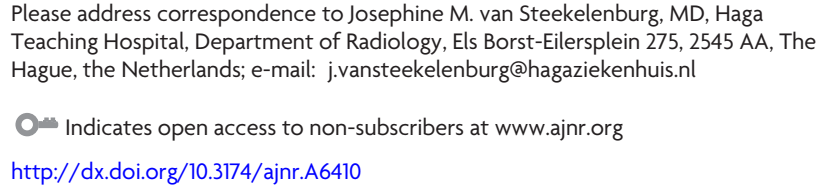

AJNR Am J Neuroradiol 41:529-34 Mar 2020 www.ajnr.org 
currently not part of the diagnostic criteria for definite MD. Most interesting, $\mathrm{EH}$ is not exclusively seen in $\mathrm{MD}$ but is also reported in healthy ears, monosymptomatic disease (vertigo, tinnitus, or hearing loss), and vestibular migraine. ${ }^{8-10}$ Based on the potential relevance of $\mathrm{EH}$ in patients suspected of having $\mathrm{MD}$, new diagnostic criteria have been proposed, differentiating primary hydropic ear disease (old terminology "definite MD" and "probable MD") from hydrops due to secondary causes such as labyrinthitis or congenital hearing loss. ${ }^{11}$

Vestibular hydrops, in particular in the saccule, seems strongly correlated with $\mathrm{MD}$, as demonstrated by recent MR imaging studies. ${ }^{12-14}$ To improve the diagnostic accuracy in patients with suspected MD based on imaging, a few recent studies introduced perilymphatic enhancement (PE) as an additional MD-discriminating parameter. ${ }^{14,15}$ However, its presence and value in other vertigo-associated inner ear pathology (VAIEP) remains unclear.

Therefore, the purpose of this study was to evaluate the presence of $\mathrm{EH}$ and the additional value of $\mathrm{PE}$ in the diagnosis of patients with MD and in patients with other VAIEP not attributable to $\mathrm{MD}$.

\section{MATERIALS AND METHODS \\ Patients}

From November 2017 to July 2018, two hundred twenty-seven consecutive patients who visited the Department of Otorhinolaryngology of our vertigo referral center (Haga Teaching Hospital, The Hague) with inner ear pathology and were suspected of having MD were retrospectively analyzed. Inclusion criteria were 18 years of age or older and a clinical diagnosis of definite MD or probable MD according to the 2015 updated Bárány criteria. ${ }^{1}$ Patients not fulfilling the criteria for definite or probable MD were included if they had attacks of vertigo with or without hearing loss and with or without tinnitus (other VAIEP). Exclusion criteria were prior operations of the inner ear, an insufficient medical record, or a technically inadequate MR imaging (motion artifacts, insufficient CSF suppression on 3D-FLAIR).

Patient anamnestic characteristics and hearing tests were evaluated twice by 3 otorhinolaryngologists, independently and blinded to the MR imaging results. Diagnoses were assigned for each ear separately, according to the latest Bárány criteria. ${ }^{1}$ Patients' ears were confined to 1 of the 4 groups: definite $\mathrm{MD}$, probable MD, other VAIEP, or asymptomatic (contralateral MD and other VAIEP ears). Consensus judgment was reached if evaluations were not congruent. This institutional review board-approved study was performed with a waiver of informed consent.

\section{Imaging Protocol}

All patients underwent delayed 3T MR imaging (Magnetom Skyra; Siemens, Erlangen, Germany) using a 20-channel array head coil, 4 hours after intravenous gadolinium $(30 \mathrm{~mL}$ of gadoterate meglumine, Dotarem; Guerbet, Aulnay-sous-Bois, France). Patients were evaluated in the supine position with additional fixation between the patient's head and the receiver coil.

High-resolution T2 sampling perfection with applicationoptimized contrasts by using different flip angle evolution (SPACE sequence; Siemens) images of the inner ear were obtained for anatomic reference using the following parameters: $\mathrm{FOV}=160 \mathrm{~mm}$, section thickness $=0.5 \mathrm{~mm}$, $\mathrm{TR}=$ $1400 \mathrm{~ms}, \mathrm{TE}=155 \mathrm{~ms}$, number of excitations $=1$, flip angle $=$ $120^{\circ}$, matrix $=320 \times 320$, bandwidth $=289 \mathrm{~Hz} /$ pixel, turbo factor $=96$, voxel size $=0.5 \times 0.5 \times 0.5 \mathrm{~mm}$, and acquisition time $=5$ minutes. A 3D-FLAIR sequence was performed on the basis of previously reported parameters. ${ }^{14}$ In short, we used the following parameters: FOV $=190 \mathrm{~mm}$, section thickness $=0.8 \mathrm{~mm}, \mathrm{TR}=6000 \mathrm{~ms}, \mathrm{TE}=177 \mathrm{~ms}$, number of excitations $=1, \mathrm{TI}=2000 \mathrm{~ms}$, flip angle $=180^{\circ}$, matrix $=384 \times$ 384 , bandwidth $=213 \mathrm{~Hz} /$ pixel, turbo factor $=28$, voxel size $=$ $0.5 \times 0.5 \times 0.8 \mathrm{~mm}$, and acquisition time $=14$ minutes.

\section{MR Imaging Analysis}

Images were analyzed using IntelliSpace PACS, Version 4.4 (Philips Healthcare, Best, the Netherlands). Images were scored for hydrops and visual signal intensity of the basal cochlear turn by 2 neuroradiologists (S.H. and O.D.V. with, respectively, 5 and 6 years of experience in MR imaging interpretation), independently and blinded to the clinical evaluation. EH was scored for the cochlea and vestibule separately using the 3 categories described by Barath; ${ }^{6}$ none, grade I (moderate), or grade II (severe). In addition to this grading system, a dilated saccule not confluent with the utricle was considered a mild isolated vestibular hydrops, according to a recently published modified scoring system. ${ }^{12,14} \mathrm{EH}$ was considered present when either or both the cochlea and vestibule were affected (Fig 1).

The postcontrast signal intensity of the basal cochlear turn on 3D-FLAIR images was scored both visually and quantitatively. Visually increased enhancement was defined as higher signal intensity compared with the contralateral ear or as matching the visual intensity level of patients with acute bloodlabyrinth barrier breakdown/acute inflammation as shown in Fig 2. Quantitative signal intensity was scored by 1 of the authors (L.M.H.d.P.) and was calculated as the signal intensity ratio (SIR) with an oval symmetric ROI measurement in the basal cochlear turns divided by a reference measurement of $0.5 \mathrm{~cm}^{2}$ in the left middle cerebellar peduncle using the multiplanar reformation (Fig 3). Shi et $\mathrm{al}^{15}$ and Tagaya et $\mathrm{al}^{16}$ used the cerebellar hemispheres as a reference measurement, whereas Yamazaki et $\mathrm{al}^{17}$ used the medulla oblongata. In the present study, we evaluated the homogeneity of the left middle cerebellar peduncle, cerebellar hemisphere, pons, and temporal muscle (data not shown). The former proved to be the most consistent and was accordingly used as a reference to calculate the SIR.

\section{Statistical Analysis}

Interobserver agreement between clinicians and neuroradiologists was calculated using the Cohen $\kappa$ test. The Fisher exact test was used to compare the difference in the presence of $\mathrm{EH}$ and visual PE between the groups. For quantitative PE analysis, a generalized estimating equation was performed. Sensitivity, specificity, positive predictive value, and negative predictive value were calculated. Among patients, a wide variability in measured PE led to the inability to quantify an absolute PE cutoff. Therefore, the added value of measured $\mathrm{PE}$ on $\mathrm{EH}$ and visual $\mathrm{PE}$ was calculated by adding the presence of measured PE asymmetry to the 

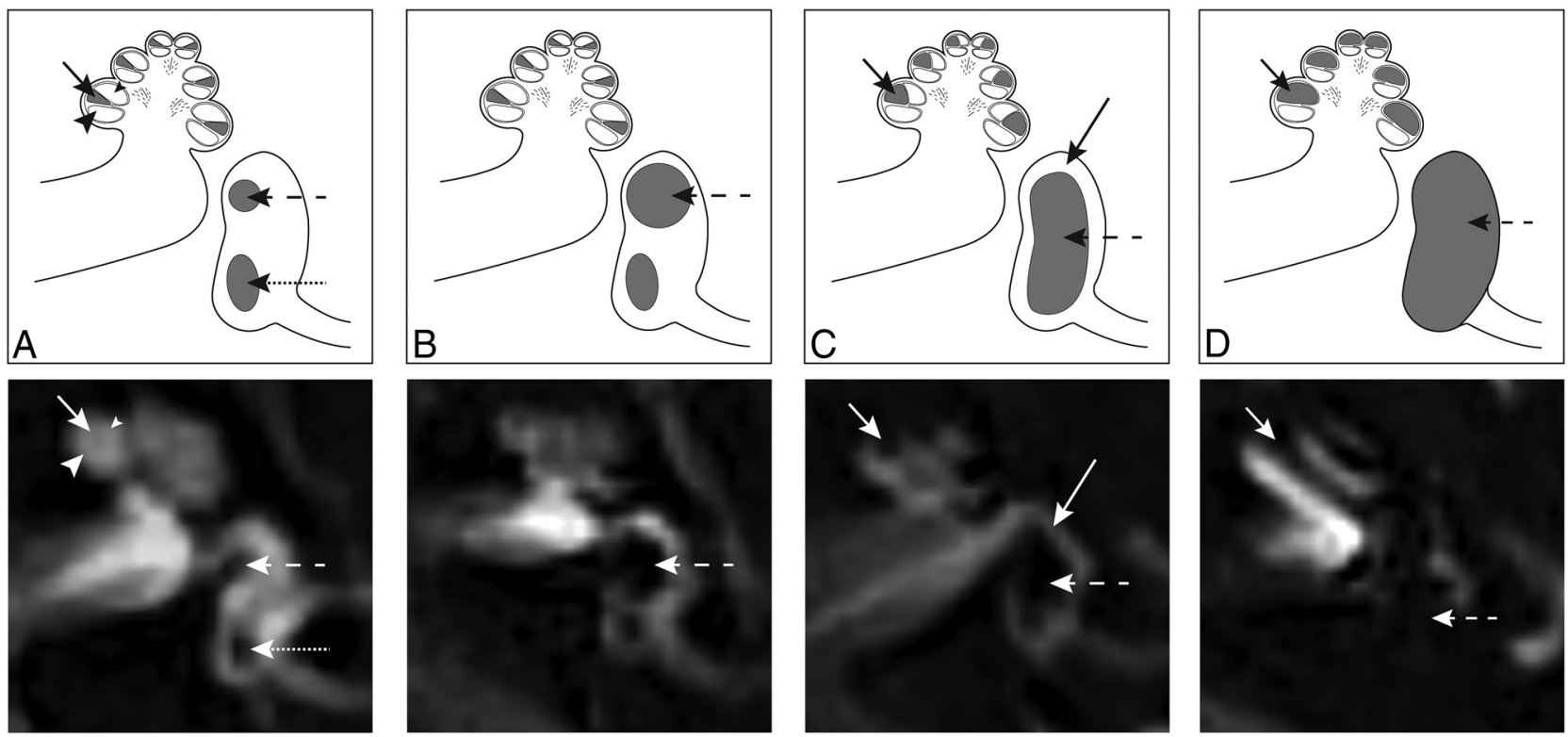

FIG 1. Axial delayed gadolinium-enhanced 3D-FLAIR MR imaging centered at the pars inferior of the vestibule, with graphic correlations. A, Normal labyrinth: saccule (dashed arrow), utricle (dotted arrow), scala media (short arrow), scala vestibuli (small arrowhead), and scala tympani (large arrowhead). B, Mild vestibular EH: the saccule (dashed arrow) is equal in size or larger than the utricle, but not confluent. C, Moderate vestibular $\mathrm{EH}$ with confluence of the saccule and utricle that encompasses $>50 \%$ of the vestibule (dashed arrow). A rim of surrounding perilymph remains visible (long arrow). Moderate cochlear EH with dilation of the scala media (short arrow), resulting in partial obliteration of the scala vestibuli. $D$, Severe vestibular EH with total effacement of the perilymphatic space in the vestibule (dashed arrow). Severe cochlear EH with complete obliteration of the scala vestibuli (short arrow).

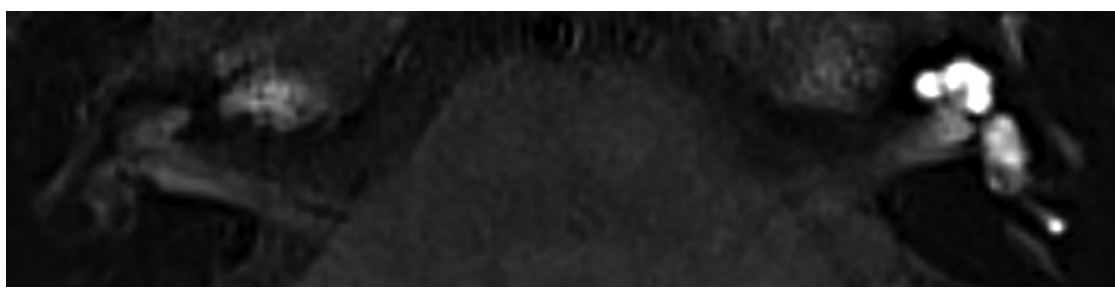

FIG 2. Axial 3D-FLAIR image 4 hours after intravenous gadolinium at the midcochlear level in a patient with unilateral left-sided sudden deafness, showing diffuse perilymphatic enhancement in the cochlea and vestibule.

equation in patients with unilateral definite MD. The other VAIEP group is considered a control group unless specifically stated otherwise. A $P$ value $<.05$ was considered significant.

\section{RESULTS}

Two hundred twenty consecutive patients from the outpatient clinic were included (127 women and 93 men; median age, 55.8 years; range, 21.5-83.2 years; median duration of sickness, 3.0 years; range, $0.005-43.0$ years). Seven patients were excluded from analysis due to a prior surgical history $(n=2)$, an insufficient medical record $(n=3)$, and technically inadequate MR imaging $(n=2)$.

In this cohort, 19 patients were diagnosed with bilateral definite MD; 111, with unilateral definite MD (of which 5 with a contralateral other VAIEP ear); 2, with bilateral probable MD; 10, with unilateral probable MD (of which 2 with a contralateral other VAIEP ear); 43, with bilateral ears with other VAIEP; and 35 , with unilateral ears with other VAIEP. Definite diagnoses of other VAIEP ears not attributable to MD are listed in Table 1.
The interobserver agreement among the clinicians to assess the diagnosis and among the neuroradiologists to assess $\mathrm{PE}$ and $\mathrm{EH}$ is shown in Table 2.

The presence of $\mathrm{EH}$ in the 4 patient categories is shown in Table 3. This results in a sensitivity of 0.92 and specificity of 0.93 for definite MD ears compared with other VAIEP ears (Table 4). The MD ears (probable and definite combined) showed a sensitivity of 0.90 and specificity of 0.93 , whereas the probable MD ears alone demonstrated a sensitivity and specificity of, respectively, 0.64 and 0.93 . No significant differences in $\mathrm{EH}$ were found between the asymptomatic ears and the other VAIEP ears (respectively, $4.7 \%$ and $7.0 \%$; Fisher exact test, $P=.45$ ).

The results of visually scored $\mathrm{PE}$ in different groups are listed in Table 3. Increased PE was more prevalent in definite and probable MD ears compared with other VAIEP ears (respectively, $P<$ .001 and $P=.003$ ) and asymptomatic ears (both, $P<.001$ ).

In addition, a significant difference was found in the presence of PE in other VAIEP ears compared with asymptomatic ears $(P<.05)$ as illustrated in Fig 2.

The results of the quantitative measurements of $\mathrm{PE}$ are shown in Table 5. The SIR of the clinically affected definite MD ears showed an increased PE of the basal cochlear turn compared with other VAIEP ears $(P<.001)$. The probable MD ears showed no differences in the SIR compared with other VAIEP ears $(P=$ $.17)$ and definite $\mathrm{MD}$ ears $(P=.06)$. 


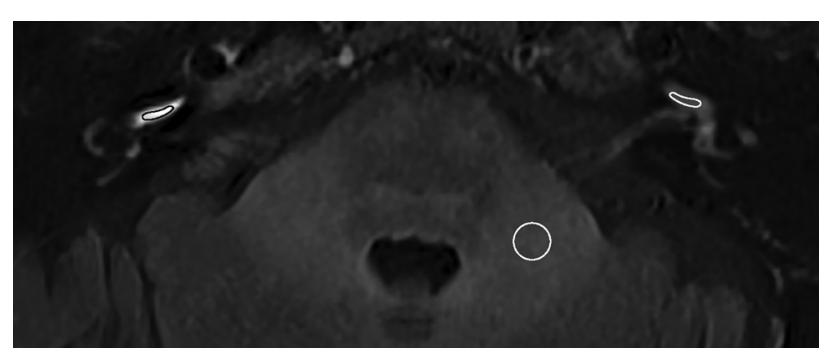

FIG 3. Axial 3D-FLAIR image 4 hours after intravenous gadolinium at the level of the basal cochlear turn of a patient with unilateral rightsided definite MD and a visually increased perilymphatic enhancement. The basal cochlear turn (oval) and the left middle cerebellar peduncle (circle) indicate the region of interest to calculate the SIR.

\section{Table 1: Clinical diagnosis of ears with other VAIEP}

\begin{tabular}{lc}
\multicolumn{1}{c}{ Clinical Diagnosis } & $\begin{array}{c}\text { Ears }(\boldsymbol{n}=128) \\
(\%)\end{array}$ \\
\hline Autoimmune inner ear disease & $2(1.6)$ \\
Benign paroxysmal positional vertigo & $6(4.7)$ \\
Cochlear migraine & $1(0.8)$ \\
Fluctuating low-to-medium frequency & $3(2.3)$ \\
$\quad$ sensorineural hearing loss eci & \\
Focal monostotic fibrous dysplasia & $1(0.8)$ \\
Hyperventilation & $14(10.9)$ \\
Labyrinthitis & $1(0.8)$ \\
Migraine & $3(2.3)$ \\
Presbycusis & $10(7.8)$ \\
Schwannoma & $1(0.8)$ \\
Sudden deafness & $10(7.8)$ \\
Tinnitus eci & $1(0.8)$ \\
Vertigo eci & $43(33.6)$ \\
Vestibular migraine & $24(18.8)$ \\
Vestibular neuritis & $8(6.3)$ \\
\hline
\end{tabular}

Note:-eci indicates e causa ignota (Latin for no cause found).

Table 2: Interobserver agreement

\begin{tabular}{lc}
\hline & $\kappa(95 \% \mathrm{Cl})$ \\
\hline Clinicians & $0.81(0.73-0.88)$ \\
Neuroradiologists & \\
EH (cochlear and/or vestibular) & $0.92(0.88-0.97)$ \\
Cochlear hydrops & $0.93(0.89-0.98)$ \\
Vestibular hydrops & $0.92(0.87-0.97)$ \\
PE visual & $0.90(0.85-0.96)$ \\
\hline
\end{tabular}

Four patients with unilateral definite MD showed no evidence of $\mathrm{EH}$. In addition, the quantified PE was not increased in the clinically affected ear compared with the contralateral asymptomatic ear. Six of the 10 patients with unilateral definite MD with EH but without visually increased PE showed an increased measured PE in their symptomatic ear compared with their asymptomatic ear.

The combination of $\mathrm{EH}$ and visually increased $\mathrm{PE}$ was present in $81.9 \%$ of the definite MD ears, whereas it was seen in only $3.1 \%$ of the ears with other VAIEP $(P<.001)$. Consequently, this combination increased the specificity in definite MD from 0.93 to 0.97 compared with $\mathrm{EH}$ alone (positive predictive value from 0.94 to 0.97 and decreased the negative predictive value from 0.91 to 0.82 and sensitivity from 0.92 to 0.82 ). The sensitivity increased to 0.86 when measured PE was added as shown in Table 4. The combination of EH and visually increased PE was seen in $42.9 \%$ of the probable MD ears, resulting in a sensitivity of 0.43 and specificity of 0.97 .

The 4 ears with other VAIEP that demonstrated the combination of $\mathrm{EH}$ and $\mathrm{PE}$ were diagnosed with vestibular migraine $(n=3)$ and autoimmune inner ear disease $(n=1)$.

\section{DISCUSSION}

The present study shows that EH and increased PE are frequently present in patients with $\mathrm{MD}$, whereas this combination is uncommon in patients with other VAIEP. Furthermore, the study emphasizes the relevance of $\mathrm{EH}$ as a hallmark of definite $\mathrm{MD}$ because vestibular or cochlear $\mathrm{EH}$ or both were present in $91.9 \%$ of the definite MD ears. This finding is in concordance with previously published studies with an $\mathrm{EH}$ prevalence ranging from $95 \%$ to $96 \%{ }^{6,15}$ In our dataset, $\mathrm{EH}$ is seen in only $4.7 \%$ of the asymptomatic ears, whereas percentages of $6 \%$ and $22 \%$ have been documented in contralateral MD ears in other studies. ${ }^{6,8}$ Even in patients with other VAIEP, a clinically relevant group, $\mathrm{EH}$ was demonstrated in only $7 \%$ of symptomatic ears. This finding is in line with previously published prevalence data in healthy control ears by Ito et al, ${ }^{8}$ in which $\mathrm{EH}$ (vestibular or cochlear) was present in $10 \%$ of the ears.

Recent studies suggest that vestibular hydrops is more specific for MD than cochlear hydrops. ${ }^{18,19}$ In our study, isolated $\mathrm{EH}$ (vestibular or cochlear) is a relatively scarce finding, though isolated vestibular hydrops is more pronounced in the definite MD group. Attyé et $\mathrm{al}^{12}$ demonstrated that half of patients with $\mathrm{MD}$ presented with inversion of the saccule-to-utricle ratio, whereas this was not present in the healthy subjects. This finding is in concordance with a recent published study by Shi et al. ${ }^{13}$ They showed that vestibular hydrops is more common in patients with definite MD compared with cochlear hydrops, ${ }^{13}$ though saccular hydrops may be a reflection of sensorineural hearing loss rather than $\mathrm{MD} \cdot{ }^{20,21} \mathrm{MR}$ imaging evaluation of $\mathrm{EH}$ is robust, reflected in a high interobserver agreement ranging from 0.92 for the vestibule to 0.93 for cochlear findings (normal and abnormal). This level of agreement is higher than the clinical interobserver agreement to assess the diagnosis, which is in line with a previously published study. ${ }^{14}$

The definite MD ears showed increased PE both visually and in quantitative measurements compared with asymptomatic ears. This is in concordance with previously published studies, though references for the signal intensity ratio are different. Shi et $\mathrm{al}^{15}$ and Tagaya et $\mathrm{al}^{16}$ used the cerebellar hemispheres and found a difference in the SIR in the affected ear compared with the contralateral ear in patients with $\mathrm{MD}$, whereas Yamazaki et $\mathrm{al}^{17}$ used the medulla oblongata. In our study, the left middle cerebellar peduncle was used as a reference to calculate the SIR.

The ears with other VAIEP showed an increased PE compared with asymptomatic ears. According to Kim et $\mathrm{al}^{22}$ increased PE was also seen on the affected side with sudden sensorineural hearing loss and vestibular neuritis compared with the unaffected side. This finding shows that increased PE is a marker of disease activity in the inner ear, rather than exclusively seen in definite $\mathrm{MD}$. Therefore, $\mathrm{PE}$ alone cannot be used to distinguish a definite MD ear from an ear with other VAIEP. 


\begin{tabular}{lcllc}
\hline & $\begin{array}{c}\text { Definite MD } \\
(\boldsymbol{n}=149)(\%)\end{array}$ & $\begin{array}{c}\text { Probable MD } \\
(\boldsymbol{n}=14)(\%)\end{array}$ & $\begin{array}{c}\text { Asymptomatic } \\
(\boldsymbol{n}=149)(\%)\end{array}$ & $\begin{array}{c}\text { Other VAIEP } \\
(\boldsymbol{n}=128)(\%)\end{array}$ \\
\hline EH & $137(91.9)^{\mathrm{b}}$ & $9(64.3)^{\mathrm{b}}$ & $7(4.7) P=.45$ & $9(7.0)$ \\
Vestibular EH & $133(89.3)^{\mathrm{b}}$ & $9(64.3)^{\mathrm{b}}$ & $7(4.7) \mathrm{NS}$ & $8(6.3)$ \\
Cochlear EH & $126(84.6)^{\mathrm{b}}$ & $8(57.1)^{\mathrm{b}}$ & $3(2.0) \mathrm{NS}$ & $4(3.1)$ \\
Isolated vestibular EH & $11(7.4) \mathrm{NS}$ & $1(7.1)(P=.47)$ & $4(2.7) \mathrm{NS}$ & $5(3.9)$ \\
Isolated cochlear EH & $4(2.7) \mathrm{NS}$ & $0(0.0) \mathrm{NS}$ & $0(0.0) \mathrm{NS}$ & $1(0.8)$ \\
PE & $123(82.6)^{\mathrm{b}}$ & $6(42.9)(P=.003)$ & $5(3.4) P=.045$ & $12(9.4)$ \\
PE and hydrops & $122(81.9)^{\mathrm{b}}$ & $6(42.9)^{\mathrm{b}}$ & $2(1.3) P=.42$ & $4(3.1)$ \\
PE and vestibular EH & $119(79.9)^{\mathrm{b}}$ & $6(42.9)^{\mathrm{b}}$ & $2(1.3) P=.42$ & $4(3.1)$ \\
PE and cochlear EH & $118(79.2)^{\mathrm{b}}$ & $6(42.9)^{\mathrm{b}}$ & $2(1.3) \mathrm{NS}$ & $3(2.3)$ \\
\hline
\end{tabular}

Note:-NS indicates not significant

${ }^{a} P E$ is scored visually.

${ }^{b} P<.001$ (Fisher Exact) compared with other VAIEP ears.

Table 4: Sensitivity, specificity, PPV, and NPV in definite MD ears

\begin{tabular}{lcccc}
\hline & Sensitivity & Specificity & PPV & NPV \\
\hline EH & 0.92 & 0.93 & 0.94 & 0.91 \\
PE & 0.83 & 0.91 & 0.91 & 0.82 \\
EH + PE visual & 0.82 & 0.97 & 0.97 & 0.82 \\
EH + PE visual or & 0.86 & 0.97 & 0.97 & 0.86 \\
$\quad$ measured & & & & \\
\hline
\end{tabular}

Note:-PPV indicates positive predictive value; NPV, negative predictive value.

Table 5: Generalized estimating equation for the mean SIR of PE with other VAIEP as a reference category

\begin{tabular}{lccc}
\hline & B & SE & $P$ Value \\
\hline Intercept & 1.094 & 0.0282 & $P<.001$ \\
Definite MD & 0.550 & 0.0590 & $P<.001$ \\
Probable MD & 0.221 & 0.1603 & $P=.167$ \\
Asymptomatic & 0.218 & 0.0844 & $P=.010$ \\
\hline
\end{tabular}

Note:-SE indicates standard error; B, beta coëfficiënt.

In patients with other VAIEP, the combination of $\mathrm{EH}$ and $\mathrm{PE}$ is seen in only $3.1 \%$ of the ears. This shows that this combination could play an essential role in diagnosing MD in this clinically relevant group. For example, an increased PE is seen in ears with idiopathic sensorineural hearing loss, ${ }^{23}$ whereas the detection of $\mathrm{EH}$ is higher in $\mathrm{MD}$ compared with sudden deafness ${ }^{24}$ or not even demonstrated at all. ${ }^{25}$

Our results demonstrate that PE measurements have an additional value compared with a visual score because the sensitivity increases from 0.82 to 0.86 when measured $\mathrm{PE}$ is added to $\mathrm{EH}$, combined with visually scored PE.

The 4 patients with unilateral definite $\mathrm{MD}$ without $\mathrm{EH}$ showed no increased measured PE. However, 1 patient demonstrated an asymmetric visual PE in the vestibule with nonvisualization of the saccule, which is presumed to be the result of an intralabyrinthine fistula. $^{26}$

Most interesting, 3 of the 4 ears with other VAIEP that showed both $\mathrm{EH}$ and $\mathrm{PE}$ were diagnosed with vestibular migraine, though this diagnosis as a separate clinical entity is under debate. ${ }^{27}$ However, with the current clinical criteria, it remains difficult to distinguish MD from vestibular migraine. This difficulty is in concordance with previously published studies suggesting that they share similar pathophysiological mechanisms ${ }^{3}$ or that describe a group of patients who fulfill both diagnostic criteria. ${ }^{28}$
Bernaerts et $\mathrm{al}^{14}$ demonstrated that the 2 most distinctive characteristics to distinguish MD ears from asymptomatic ears are cochlear PE and vestibular EH. Our study confirms that the combination of EH (vestibular or cochlear) and PE is distinctive for definite MD and shows, in addition, that this combination is rarely present in the ears with other VAIEP. Furthermore, PE alone cannot be used to distinguish a definite $\mathrm{MD}$ ear from an ear with other VAIEP.

The retrospective design of the conducted study hampers the potential to correlate the imaging findings with clinical parameters (attack frequency and time interval of last attack relative to imaging) and assess their relation with the severity of $\mathrm{EH}$ in the current grading systems. Furthermore, the group with other VAIEP, though clinically relevant, shows heterogeneous patient characteristics. This feature hampers the possibility to draw conclusions within this group. Another limitation is the presumption that a contralateral ear of a patient with definite $\mathrm{MD}$, probable $\mathrm{MD}$, and other VAIEP is considered healthy and is added to the group with asymptomatic ears.

\section{Practical Use of MR Imaging in (Suspected) Ménière Disease}

Previous studies have mainly focused on identifying inner ear abnormalities on 3D-FLAIR MR imaging by comparing symptomatic and asymptomatic ears in patients with MD. ${ }^{6,14,16-18}$ These studies showed MR imaging to be highly sensitive and specific in discriminating the affected ear in patients with MD. However, considering the variable spectrum of clinical presentations in MD, a comparison with patients with other VAIEP seems relevant. ${ }^{9,29}$ The present study demonstrates the value of delayed gadoliniumenhanced 3D-FLAIR MR imaging in diagnosing MD in a cohort with a wide range of vertigo-associated inner ear diseases and shows that the combination of EH and increased PE is uncommon in patients with other VAIEP; this finding could be of particular relevance in patients in whom an atypical clinical presentation hampers a definite diagnosis, as is the case with probable MD. Although the number of patients with probable MD in our cohort is limited, $43 \%$ of these patients demonstrated the combination of EH and increased PE. On the basis of our study results, this finding suggests a (definite) MD diagnosis, which may alter treatment strategies. However, longitudinal research is necessary to evaluate clinical progression to definite MD.

In $20 \%$ of patients with $\mathrm{MD}$, the vestibular and cochlear symptoms coincide after $>5$ years, resulting in diagnostic delay. ${ }^{9}$ Moreover, the lower interobserver agreement in the diagnoses of the clinicians compared with the hydrops scoring of neuroradiologists reflects the additional value of imaging.

Even in patients with evident, clinically definite MD, imaging is helpful in the evaluation of hydrops when conservative treatment fails, or in assessing possible bilateral hydropic disease (with unilateral symptoms) before considering, for example, 
sacrificing 1 ear with a destructive inner ear operation in selected cases. $^{30,31}$

\section{CONCLUSIONS}

The combined presence of $\mathrm{EH}$ and increased $\mathrm{PE}$ is associated with the clinical diagnosis of definite $\mathrm{MD}$ and not with other VAIEP. These findings may help to differentiate patients with vertigo attributable to $\mathrm{MD}$.

\section{ACKNOWLEDGMENTS}

The authors thank Vera de Pont and Anne de Bokx for their assistance in preparing the graphics.

Disclosures: Berit M. Verbist-UNRELATED: Payment for Lectures Including Service on Speakers Bureaus: Bayer Pharmaceuticals. Sebastiaan HammerRELATED: Grant: Dutch Society of Radiology, Comments: A grant was awarded to assess the technical feasibility of MRI-evaluated endolymphatic hydrops and allow development of optimizing imaging techniques.

\section{REFERENCES}

1. Lopez-Escamez JA, Carey J, Chung WH, et al; Korean Balance Society. Diagnostic criteria for Menière's disease. J Vestib Res Equilib Res 2015;25:1-7 CrossRef Medline

2. Nakashima T, Pyykkö I, Arroll MA, et al. Meniere's disease. Nat Rev Dis Primer 2016;2:16028 CrossRef Medline

3. Pyykkö I, Manchaiah V, Färkkilä M, et al. Association between Ménière's disease and vestibular migraine. Auris Nasus Larynx 2019;46:724-33 CrossRef Medline

4. Neff BA, Staab JP, Eggers SD, et al. Auditory and vestibular symptoms and chronic subjective dizziness in patients with Ménière's disease, vestibular migraine, and Ménière's disease with concomitant vestibular migraine. Otol Neurotol 2012;33:1235-44 CrossRef Medline

5. Cairns H, Hallpike F. Observations on the pathology of Meniere's syndrome. Proc R Soc Med 1938;31:1317-36 Medline

6. Barath $K$. Detection and grading of endolymphatic hydrops in Meniere disease using MR imaging. AJNR Am J Neuroradiol 2014; 35:1387-92 CrossRef Medline

7. Naganawa S, Nakashima T. Visualization of endolymphatic hydrops with MR imaging in patients with Ménière's disease and related pathologies: current status of its methods and clinical significance. Jpn J Radiol 2014;32:191-204 CrossRef Medline

8. Ito T, Kitahara T, Inui $\mathrm{H}$, et al. Endolymphatic space size in patients with Meniere's disease and healthy controls. Acta Otolaryngol 2016;136:879-82 CrossRef Medline

9. Pyykkö I, Nakashima T, Yoshida T, et al. Ménière's disease: a reappraisal supported by a variable latency of symptoms and the MRI visualisation of endolymphatic hydrops. BMJ Open 2013;3:e00155510 CrossRef Medline

10. Nakada T, Yoshida T, Suga K, et al. Endolymphatic space size in patients with vestibular migraine and Ménière's disease. J Neurol 2014;261:2079-84 CrossRef Medline

11. Gürkov R, Hornibrook J. On the classification of hydropic ear disease (Menière's disease). HNO 2018;66:455-63 CrossRef Medline

12. Attyé A, Eliezer M, Boudiaf N, et al. MRI of endolymphatic hydrops in patients with Meniere's disease: a case-controlled study with a simplified classification based on saccular morphology. Eur Radiol 2017;27:3138-46 CrossRef Medline

13. Shi S, Zhou F, Wang W. 3D-real IR MRI of Meniere's disease with partial endolymphatic hydrops. Am J Otolaryngol 2019;40:589-93 CrossRef Medline
14. Bernaerts A, Vanspauwen R, Blaivie C, et al. The value of four stage vestibular hydrops grading and asymmetric perilymphatic enhancement in the diagnosis of Menière's disease on MRI. Neuroradiology 2019;61:421-29 CrossRef Medline

15. Shi S, Guo P, Wang W. Magnetic resonance imaging of Ménière's disease after intravenous administration of gadolinium. Ann Otol Rhinol Laryngol 2018;127:777-82 CrossRef Medline

16. Tagaya M, Yamazaki M, Teranishi M, et al. Endolymphatic hydrops and blood-labyrinth barrier in Ménière's disease. Acta Otolaryngol 2011;131:474-79 CrossRef Medline

17. Yamazaki M, Naganawa S, Tagaya M, et al. Comparison of contrast effect on the cochlear perilymph after intratympanic and intravenous gadolinium injection. AJNR Am J Neuroradiol 2012;33:773-78 CrossRef Medline

18. Li X, Wu Q, Sha Y, et al. Gadolinium-enhanced MRI reveals dynamic development of endolymphatic hydrops in Ménière's disease. Braz J Otorhinolaryngol 2018 Dec 20. [Epub ahead of print] CrossRef Medline

19. Yoshida T, Sugimoto S, Teranishi M, et al. Imaging of the endolymphatic space in patients with Ménière's disease. Auris Nasus Larynx 2018;45:33-38 CrossRef Medline

20. Attyé A, Eliezer M, Medici $M$, et al. In vivo imaging of saccular hydrops in humans reflects sensorineural hearing loss rather than Meniere's disease symptoms. Eur Radiol 2018;28:2916-22 CrossRef Medline

21. Sepahdari AR, Ishiyama G, Vorasubin N, et al. Delayed intravenous contrast-enhanced 3D FLAIR MRI in Meniere's disease: correlation of quantitative measures of endolymphatic hydrops with hearing. Clin Imaging 2015;39:26-31 CrossRef Medline

22. Kim TY, Park DW, Lee YJ, et al. Comparison of inner ear contrast enhancement among patients with unilateral inner ear symptoms in MR images obtained 10 minutes and $\mathbf{4}$ hours after gadolinium injection. AJNR Am J Neuroradiol 2015;36:2367-72 CrossRef Medline

23. Pakdaman $M N$, Ishiyama $G$, Ishiyama $A$, et al. Blood-labyrinth barrier permeability in Menière disease and idiopathic sudden sensorineural hearing loss: findings on delayed postcontrast 3D-FLAIR MRI. AJNR Am J Neuroradiol 2016;37:1903-08 CrossRef Medline

24. Horii A, Osaki Y, Kitahara T, et al. Endolymphatic hydrops in Meniere's disease detected by MRI after intratympanic administration of gadolinium: comparison with sudden deafness. Acta Otolaryngol 2011;131:602-09 CrossRef Medline

25. Tagaya M, Teranishi M, Naganawa S, et al. 3 Tesla magnetic resonance imaging obtained 4 hours after intravenous gadolinium injection in patients with sudden deafness. Acta Otolaryngol 2010;130:665-69 CrossRef Medline

26. Attyé A, Eliezer M, Galloux A, et al. Endolymphatic hydrops imaging: differential diagnosis in patients with Meniere disease symptoms. Diagn Interv Imaging 2017;98:699-706 CrossRef Medline

27. Phillips J, Longridge N, Mallinson A, et al. Migraine and vertigo: a marriage of convenience? Headache 2010;50:1362-65 CrossRef Medline

28. Tabet $P$, Saliba I. Meniere's disease and vestibular migraine: updates and review of the literature. J Clin Med Res 2017;9:733-44 CrossRef Medline

29. Rauch SD. Clinical hints and precipitating factors in patients suffering from Meniere's disease. Otolaryngol Clin North Am 2010;43: 1011-17 CrossRef Medline

30. Gluth MB. On the relationship between Menière's disease and endolymphatic hydrops. Otol Neurotol 2020;41:242-49 CrossRef Medline

31. Da Costa SS, De Sousa LCA, De Toledo Piza MR. Meniere's disease: overview, epidemiology, and natural history. Otolaryngol Clin North Am 2002;35:455-95 CrossRef Medline 